\title{
NARRATIVAS ARQUEOLÓGICAS PÚBLICAS E IDENTIDADES INDÍGENAS EN CATAMARCA.
}

\author{
Marcos Quesada* \\ Enrique Moreno ** \\ Marcos Gastaldi***
}

\begin{abstract}
Resumen: Nos interesa explorar aquí el rol que juegan las narrativas arqueológicas en la conformación del imaginario de lo indígena y su historia en la provincia de Catamarca, Argentina. Por medio de un análisis espacial y discursivo de la exhibición del "Museo Arqueológico Adán Quiroga", sostendremos que estas narrativas relegan lo indígena al pasado prehispánico, al tiempo que afirman su desaparición durante los primeros tiempos de la colonia. Estas narrativas no sólo podrían erosionar las posibilidades de autoafirmación identitaria por parte de los mismos indígenas, sino que crean dudas en cuanto a la legitimidad de tales identidades y los derechos que le asisten.
\end{abstract}

Palabras clave: narrativas, arqueología pública, identidades, indígenas, museo

El avance de la lógica de producción capitalista sobre tierras que habían permanecido bajo el usufructo de comunidades campesinas, ha cobrado un nuevo impulso en la última década en la provincia de Catamarca. La apropiación de estos espacios, que en general se trata de los llamados "campos comuneros", se debe a una variedad de procesos económicos según el lugar de la provincia donde se produce. La instalación de empresas agroindustriales que aprovechan las políticas estatales de diferimiento impositivo, el auge de la minería en gran escala, ciertos proyectos de

\footnotetext{
* Escuela de Arqueología, Universidad Nacional de Catamarca y CONICET - mkesada@yahoo.com.ar **Escuela de Arqueología, Universidad Nacional de Catamarca y CONICET - enalmor@yahoo.com ***Museo de Antropología, Universidad Nacional de Córdoba y CONICET - mrgastaldi@yahoo.com.ar
}

conformación de parques nacionales o áreas protegidas, son sólo algunos de ellos. Los conflictos que se generaron alrededor de estos procesos dieron lugar, en algunos casos, a la organización de acciones colectivas orientadas a impedir la enajenación (por ejemplo Pizarro 2000, Pizarro y Moreno 2003). Sin embargo, a diferencia de lo que sucedió en otras provincias, muy pocas de estas movilizaciones campesinas llevaron a su conformación como comunidades indígenas, aún cuando la reforma constitucional del año 1994 incluyó una serie de amparos y garantías para quienes se reconocieran como tales. Las causas de tal fenómeno deben ser múltiples, complejas y concurrentes. En este trabajo nos interesa explorar el probable rol que juegan las narrativas arqueológicas dirigidas al gran público en la conformación del imaginario de lo indígena y su historia en Catamarca. Por medio de un análisis espacial de la exhibición del museo 
arqueológico Adán Quiroga, sostendremos que estas narrativas relegan lo indígena al pasado prehispánico, al tiempo que afirman su desaparición durante los primeros tiempos de la colonia. Estas narrativas no sólo podrían erosionar, al menos en alguna medida, las posibilidades de autoafirmación identitaria por parte de los mismos indígenas, ${ }^{1}$ sino que crean dudas en cuanto a la legitimidad de tales identidades y los derechos que les asisten.

En un trabajo reciente, Haber (1999) empleó el término ruptura metafísica para hacer referencia a la separación de los campos objetuales de la arqueología y la historia, es decir la distinción entre lo arqueológico y lo histórico. Esta demarcación disciplinaria, cuyo origen fue rastreado por el autor hasta la obra de S. Debenedetti a comienzos de la década de 1920, marcó a lo largo de casi un siglo la producción de narrativas históricas en la Argentina. La ruptura metafísica, sustentada en la supuesta discontinuidad cultural de la tradición aborigen tras la conquista española, no sólo supuso una separación del objeto, sino también una demarcación del sujeto. De esta manera se constituyó una división entre lo histórico representando un pasado hispánico y más cercano al nosotros criollo y republicano y una arqueología representando un pasado más lejano, de otros, definido por el pasado indígena que queda como un fenómeno atrasado en el tiempo y exótico a partir de la conquista española (Funari 2006, Galloway 2006, Hall y Silliman 2006). Por ello, sus consecuencias fueron de importancia no sólo en el ámbito académico, como claramente lo señala Haber (1999), sino también en las narrativas públicas acerca de la historia que los arqueólogos producimos y por ende en la construcción del imaginario colectivo de la Nación.

Podría parecer extraño que en Catamarca, donde el pasado prehispánico es movilizado frecuentemente en los discursos y actos pú-

(1) Está claro que no del todo, puesto que recientemente, en Catamarca, dos comunidades indígenas iniciaron procesos de reconocimiento y otras están comenzando a recorrer esa senda. blicos, los arqueólogos nunca nos caracterizamos por nuestro afán de difundir los resultados de las investigaciones fuera de los ámbitos académicos. Es en los museos donde el público puede penetrar en los misteriosos saberes que, de otro modo, quedan confinados en el hermetismo de nuestro campo disciplinar. De los museos arqueológicos de Catamarca, el más importante en cuanto a antigüedad y valor de la colección es el Adán Quiroga, en la ciudad Capital. Este tiene su origen en el interés coleccionista de Salvador Narváez, sacerdote franciscano que en la década de 1930 comenzó a reunir las numerosas piezas que integran el patrimonio del museo. En 1975, mediante un convenio realizado entre la orden religiosa y la Municipalidad de la ciudad Capital, el museo quedó bajo la custodia y administración de esta última. Probablemente la organización espacial de la muestra y su guión museológico daten de esta fecha. Los autores de este texto no recordamos modificaciones significativas en los últimos 15 años. El edificio que alberga el Museo fue construido en 1943 como un complejo cultural provisto, aparte del museo, de una sala de conferencias, biblioteca y otras dependencias. Al Museo le corresponden tres salones donde se organiza la exhibición. El más amplio de ellos es el salón de arqueología (Fig. 1), luego la sala Colonial (Fig. 2) y finalmente la sala Fray Mamerto Esquiú (Fig. 3). Lo que nos interesa aquí es analizar el relato acerca de la historia que organiza la distribución espacial de la exhibición.

El principal criterio para la organización de la muestra es cronológico. La ordenación cronológica de la muestra no es ingenuamente seguida, sino que se relaciona con la idea de progreso que ha dominado buena parte del desarrollo de la arqueología que continuando lo propuesto en el siglo XVIII por el iluminismo, se centraba en la idea de una continuidad desde lo simple hacia lo complejo, con un parámetro tecnológico como fundamento explicativo, siguiendo una complejidad acumulativa y medida a partir de parámetros tecnológicos (Mc Guire 1983, 1996; Shanks y Tilley 1987). 


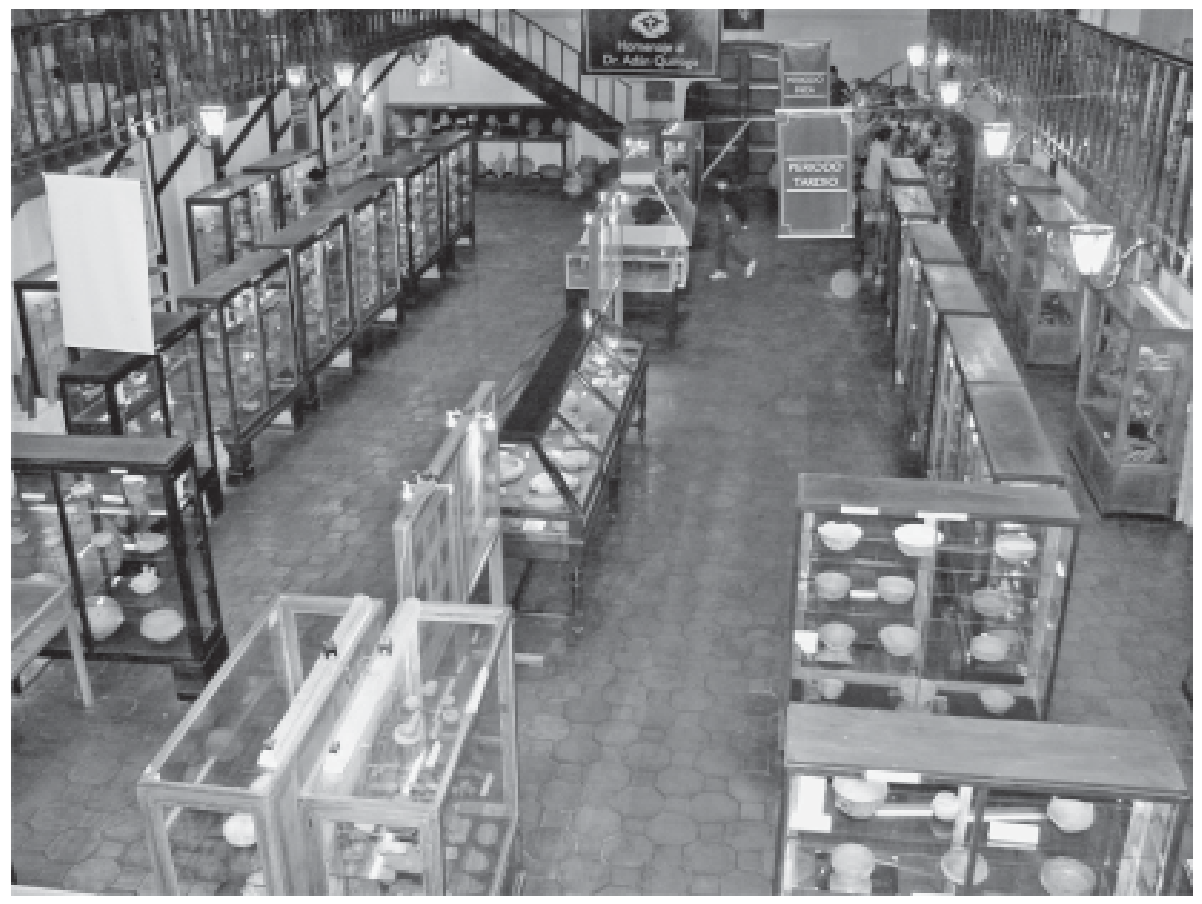

Fig. 1. Vista general de la sala de arqueología del Museo Adán Quiroga

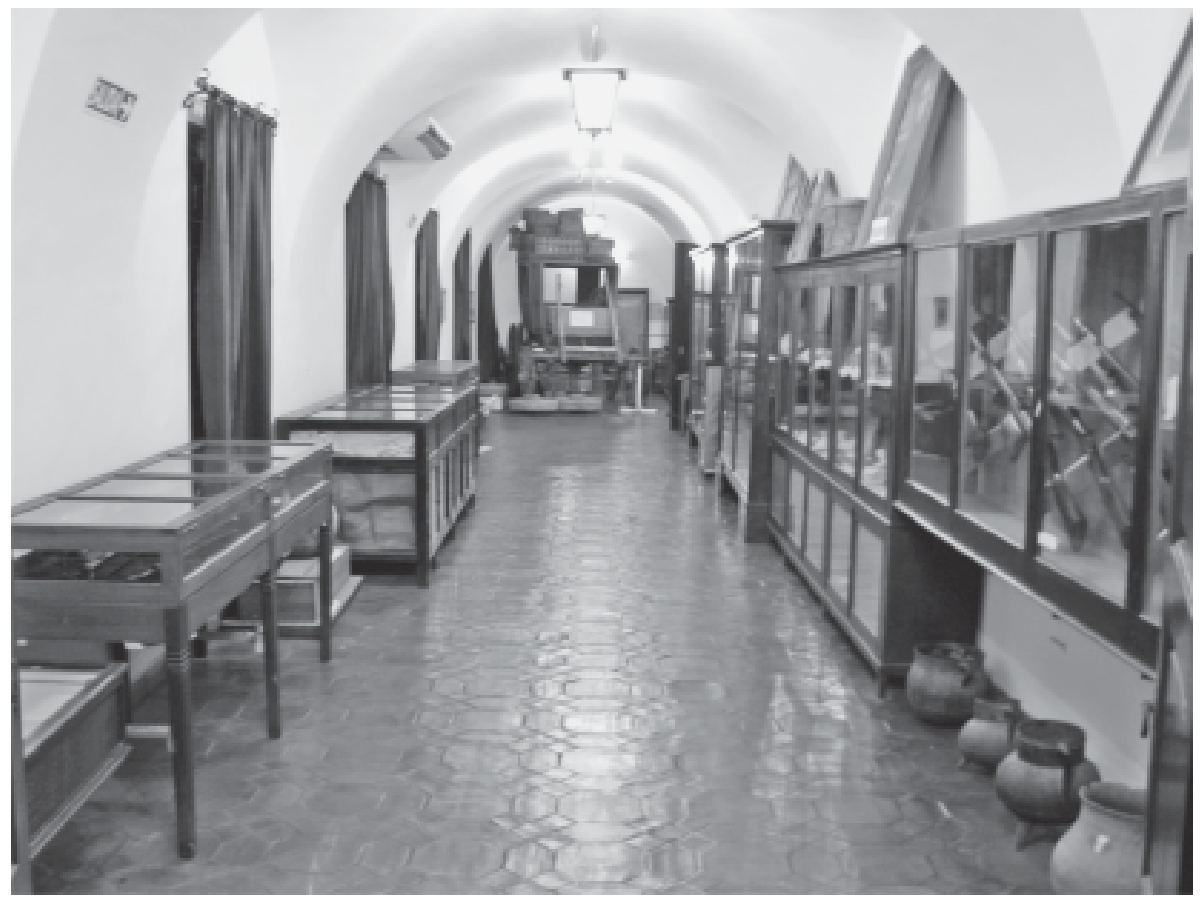

Fig. 2. Vista general de la sala de historia colonial 


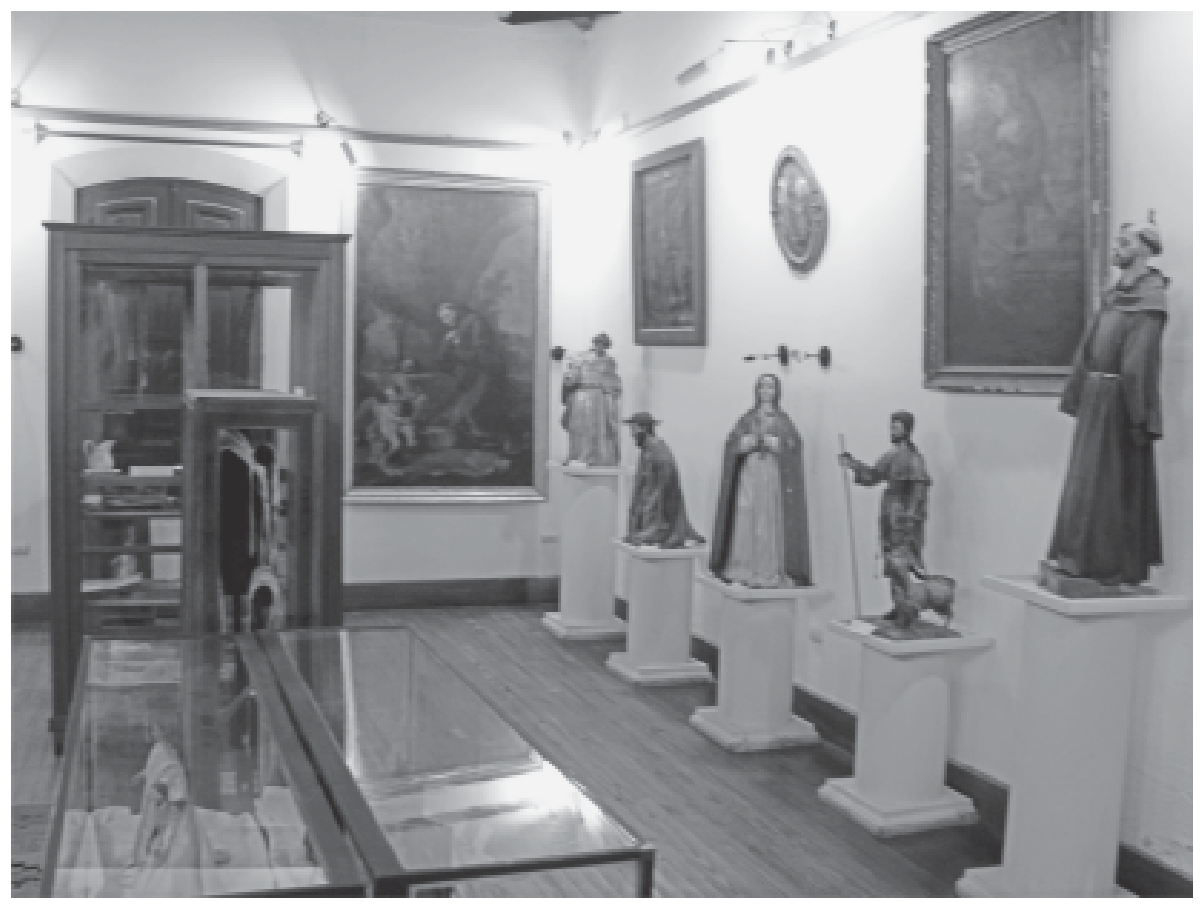

Fig. 3. Vista general de la sala Fray Mamerto Esquiú.

Este se estructura en dos niveles, por un lado se ordena en la secuencia de salas (arqueológico - colonial/religioso) y por otro lado ordena la distribución en el amplio salón de arqueología. Vamos a comenzar por este último nivel. Las vitrinas que contienen las piezas arqueológicas están dispuestas una junto a otra formando pasillos que prescriben y proscriben rígidamente la circulación. Esta suerte de laberinto conduce al visitante a lo largo del "hilo de la historia". La experiencia es la siguiente: al ingresar al salón uno se encuentra con la primera barrera (Fig. 4). Una fila de vitrinas impide el avance y deja libres dos direcciones posibles, derecha 0 izquierda. Pero antes de tomar una decisión debe uno dirigirse al escritorio ubicado justo frente a la puerta de acceso donde el empleado municipal realiza el cobro de la entrada e inmediatamente indica que la dirección "correcta" es hacia la izquierda. Al girar en la esquina se arriba a un sector demarcado con un cartel que dice
"Precerámico". 2 Ya estamos en el inicio del relato. A partir de allí circulamos entre piezas que representan aquello que, se supone, caracteriza cada período. Lo precerámico, encerrado en una única vitrina, está representado por herramientas de piedra y hueso (Fig. 6). Algunas de ellas, como las "muyunas", la azada de piedra y los morteros, bien podrían corresponder a períodos posteriores (Fig. 7).

(2) En la Figura 5 se observa el cuadro cronológico del Noroeste Argentino, confeccionado según los datos obtenidos por Alberto Rex González para el Valle de Hualfín (Departamento Belén, Provincia de Catamarca) y que es el que reproduce el Museo Adán Quiroga. El mismo divide el tiempo prehispánico del Noroeste Argentino en dos grandes períodos: precerámico y agroalfarero. El agralfarero a su vez está dividido en formativo temprano, medio y tardío. El precerámico estaría caracterizado por ocupaciones de cazadores-recolectores, que responden a una organización social muy simple. El período agroalfarero estaría conformado por grupos cada vez más desarrollados, con conjuntos cerámicos y desarrollo de la producción agrícola y el pastoreo de camélidos. 


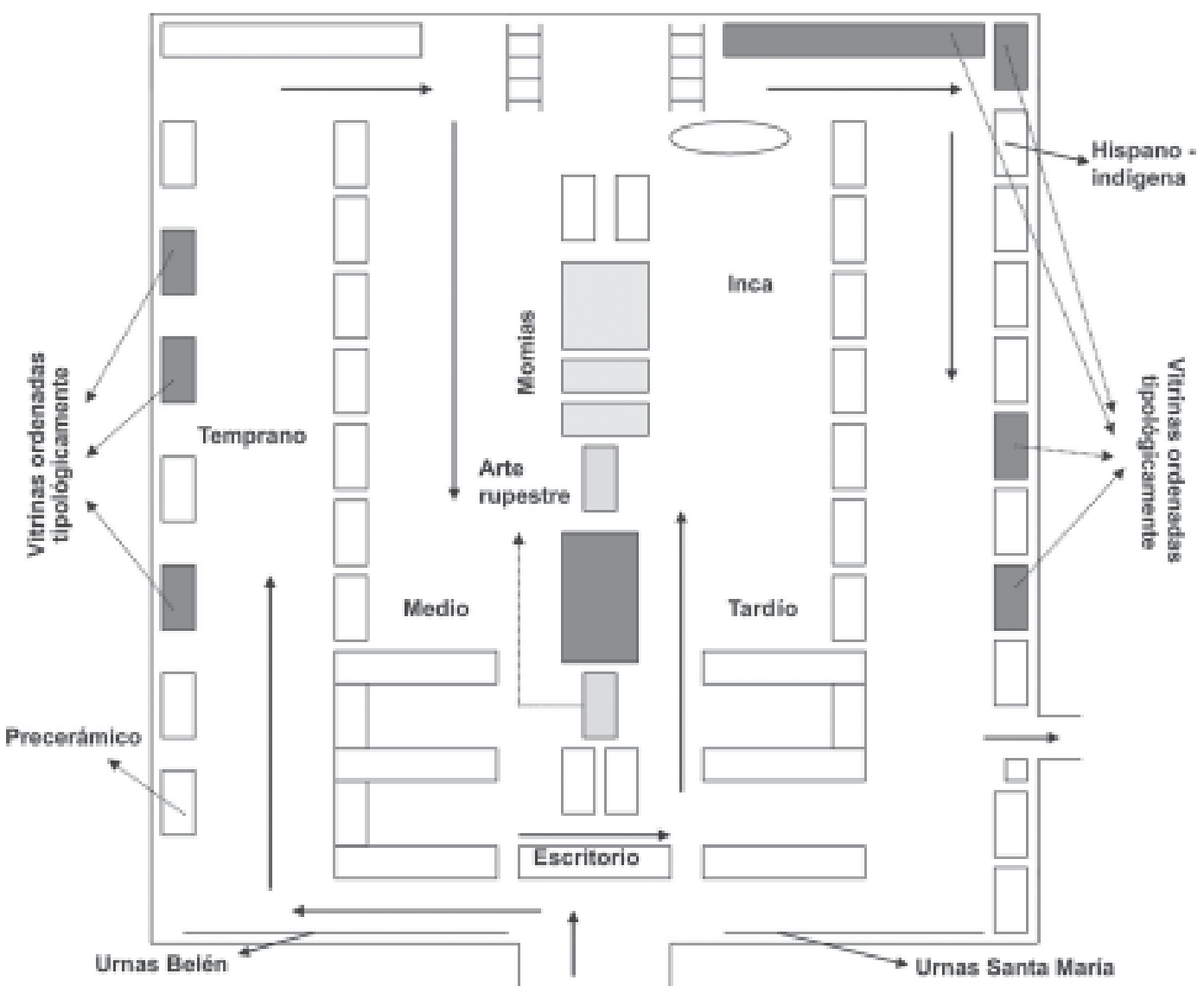

Fig. 4. Plano de circulación en la sala de arqueología.

A continuación, nos adentramos al período temprano indicado por su respectivo cartel. Lo característico aquí son las cerámicas de los estilos correspondientes a las llamadas culturas Ciénaga, Condorhuasi y Candelaria, que, si bien separadas en las vitrinas, aparecen, se sabe, mezcladas en los sitios arqueológicos. ${ }^{3}$

(3) Estas culturas fueron definidas, por la arqueología argentina, como si fueran pueblos o grupos étnicos distintos, cada uno con diferencias claras en todos los ámbitos de la vida cotidiana, separados, sobre todo, temporal y espacialmente unos de otros. Las vinculaciones entre estilo cerámico y cultura, y su correlación con la idea de pueblo o grupo étnico, se explica en virtud de que la arqueología, como así también la antropología, tendieron a representar, a
Así se arriba al fondo del salón. Allí la atención del visitante es capturada, primero, por unas vitrinas que contienen ceramios con forma de animalitos de culturas del período temprano e inmediatamente a continuación, ya regresando a la entrada, por tres vitrinas adyacentes que contienen el cuerpo disecado

sus objetos de investigación, como "totalidades". Así la cultura como totalidad uniforme, portada por un grupo de personas se expresaba materialmente en los objetos realizados por estos. De esta forma las culturas quedaban amaradas con pueblos particulares, grupos étnicos, tribus y/o razas; y la cultura material se transformaba en significante de aquellos (Jones 1996, 1997; Trigger 1989). 


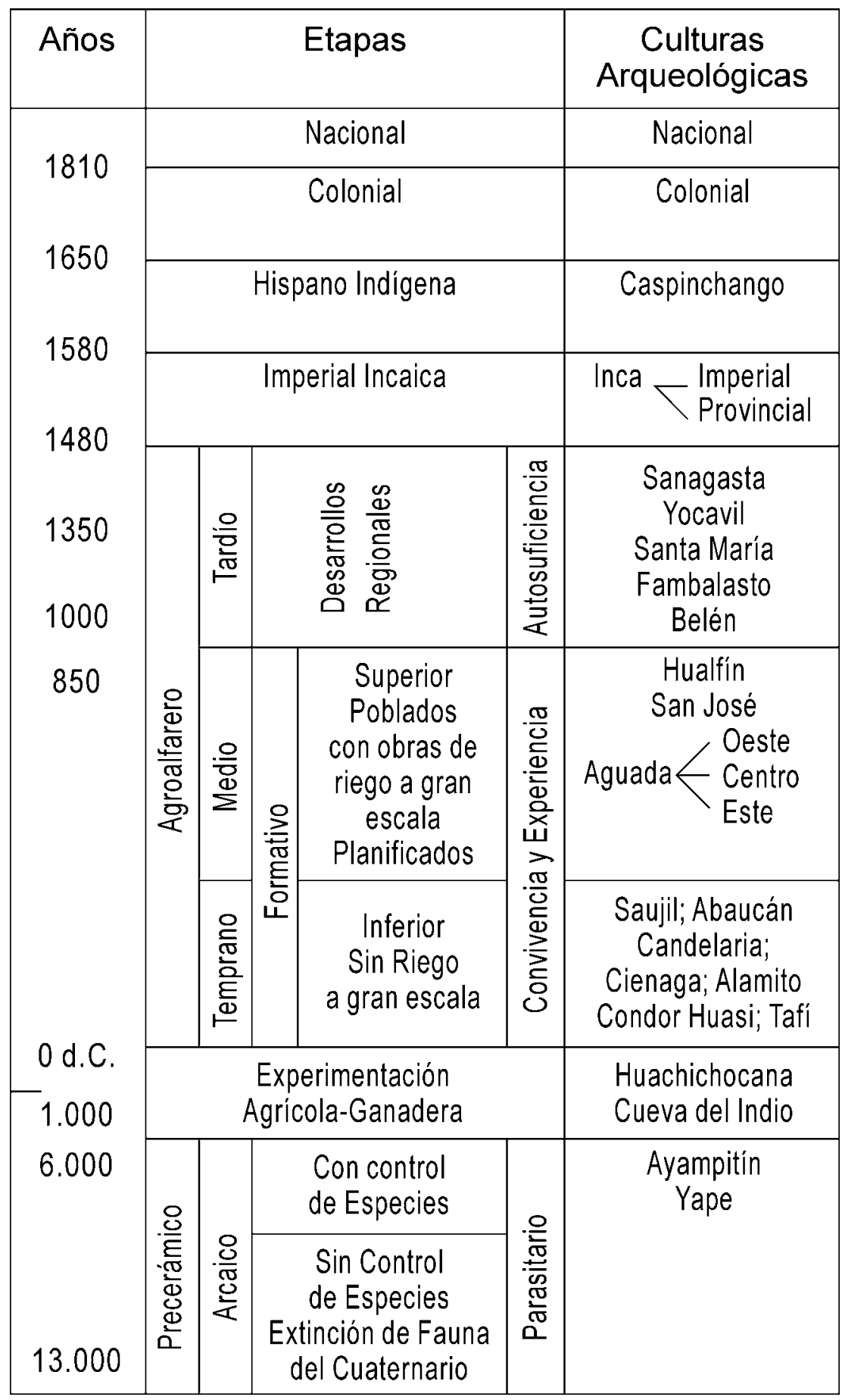

Fig. 5. Secuencia cronológica-cultural del noroeste argentino según Kriscautzky (1999). Es similar a la que se expone en el acceso a la sala de arqueología. 


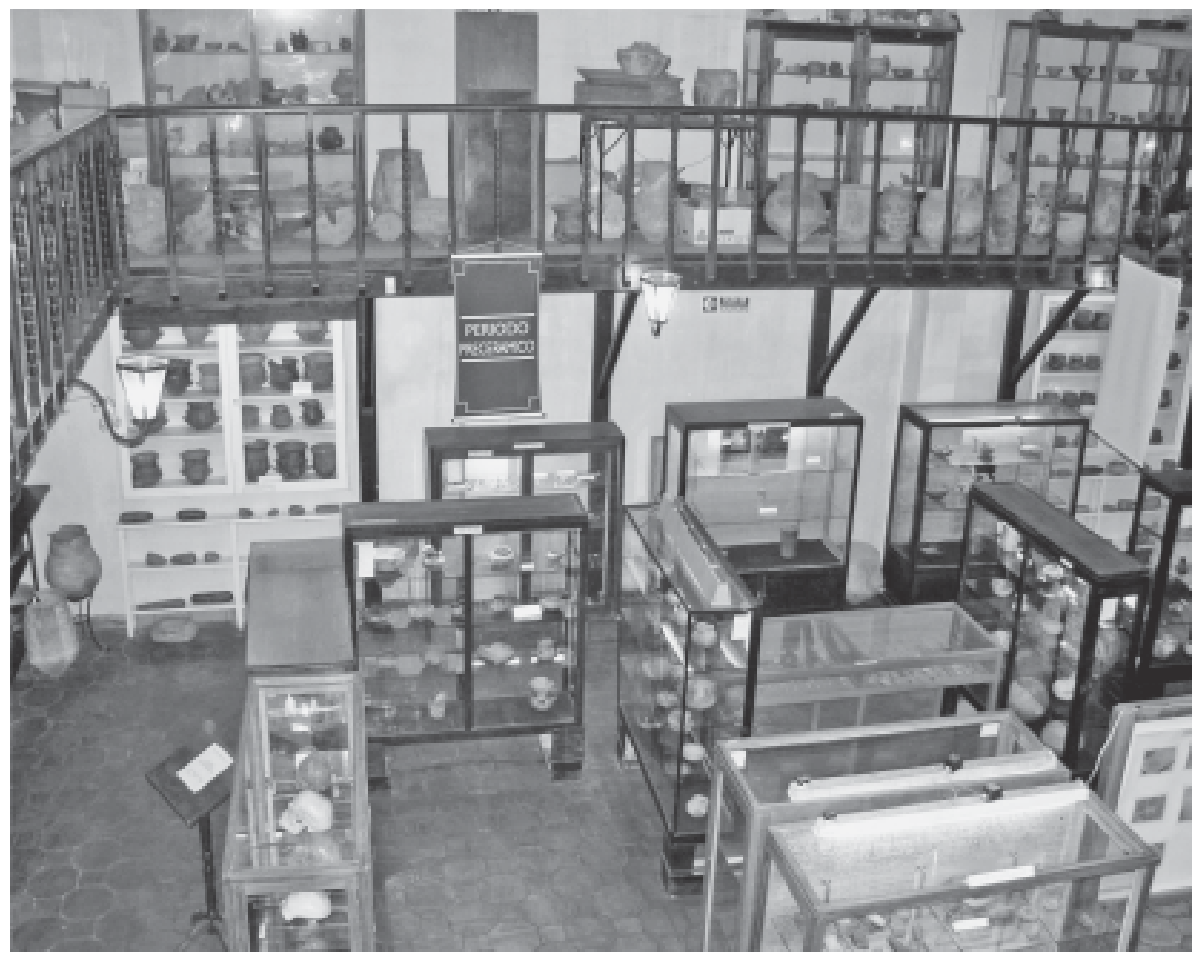

Fig. 6. Vista de la vitrina con material precerámico, sobre ella, el cartel indicador del período.

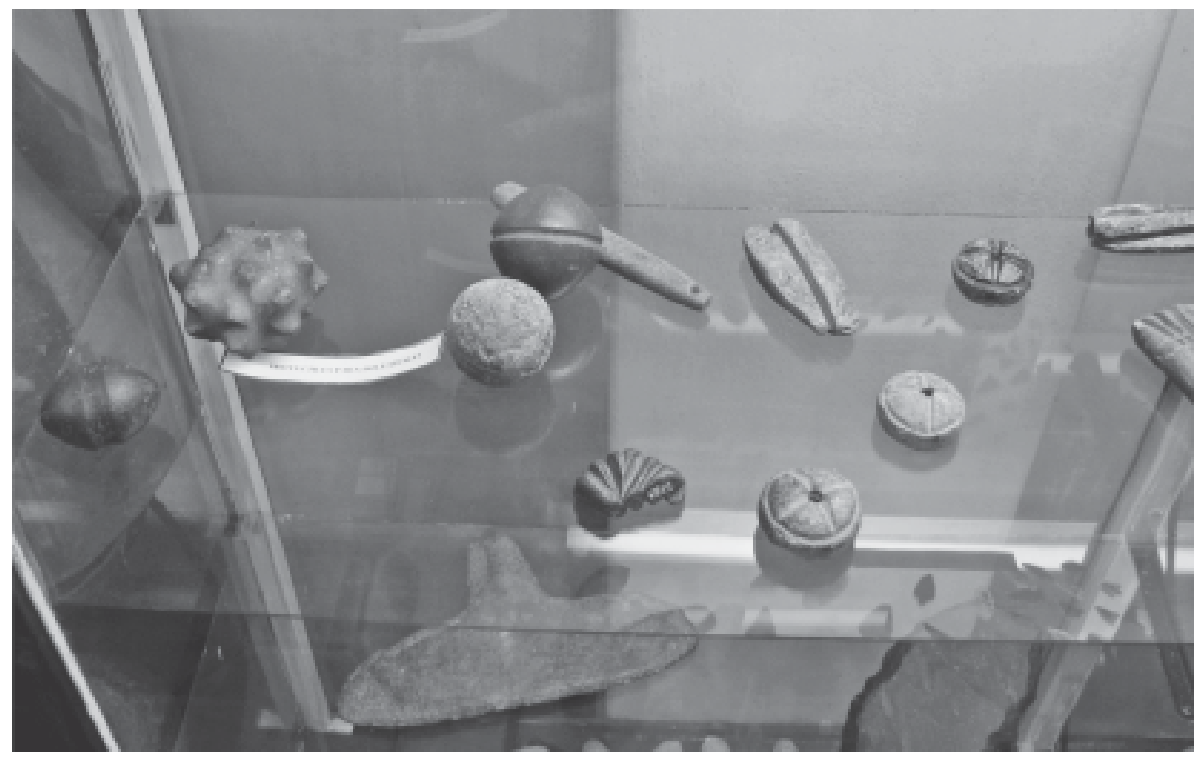

Fig. 7. Materiales exhibidos en la vitrina del período Precerámico. 
de un adulto la primera, de un niño la segunda y finalmente, un esqueleto de adulto la tercera (Fig. 8). Nos encontramos en el centro el salón. La circulación es luego dirigida por la posición de una serie de paneles con fotografías de arte rupestre y vitrinas que albergan piezas reunidas por categoría funcional (morteros y fuentes) o materia prima (objetos de piedra) (Fig. 9) y otra que contiene numerosos cráneos. El ordenamiento cronológico que fuera reemplazado en la hilera central de vitrinas, la que nos trajo nuevamente a la entrada pero ahora del otro lado del escritorio, por exhibiciones temáticas, es retomado en adelante, con rigurosidad. El extremo de la tercera hilera de vitrinas más próximo al visitante comienza con una exhibición de objetos de la cultura de La Aguada, que representa al período Medio. Luego, dirigiéndonos nuevamente al fondo del salón, circulamos entre objetos de los períodos Tardío o de Desarrollos Regionales (cerámicas conocidas como Santa María, Sanagasta,
Yokavil, discos y otros objetos de metal, etc.) e Inka (cerámica inka). Finalmente, ya en el fondo del salón, una vitrina contiene unos pocos ejemplares de vasijas conocidas como Caspinchango, que corresponden a la cerámica indígena característica de los primeros siglos de la conquista española (Fig. 10). Aquí, en el período Hispano-indígena, se completa el recorrido de la muestra arqueológica.

Cada uno de los períodos (Precerámico, Temprano, Medio, Tardío, Inka e Hispanoindígena) está señalado con el correspondiente cartel que no sólo indica el lugar de la historia en que uno se encuentra, sino que, por estar escritos de un sólo lado, señalan la forma correcta en que la historia debe ser recorrida y aprehendida reforzando textualmente la coreografía que el ordenamiento de las vitrinas impone materialmente. El recorrido histórico que acabamos de sintetizar, quizá en exceso, da cuenta de una historia prehispánica continua. La adyacencia de las

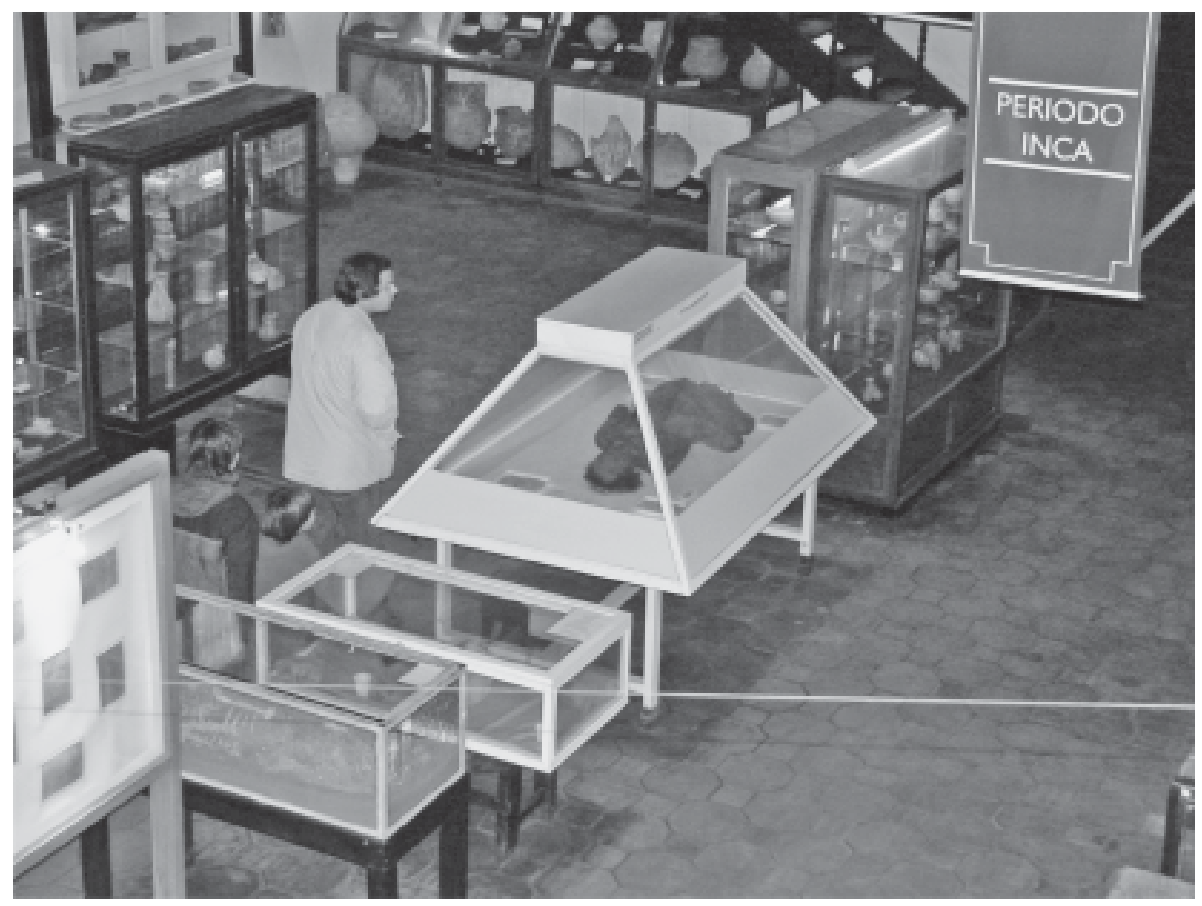

Fig. 8. Vitrinas con cuerpos momificados en el centro del salón de arqueología 


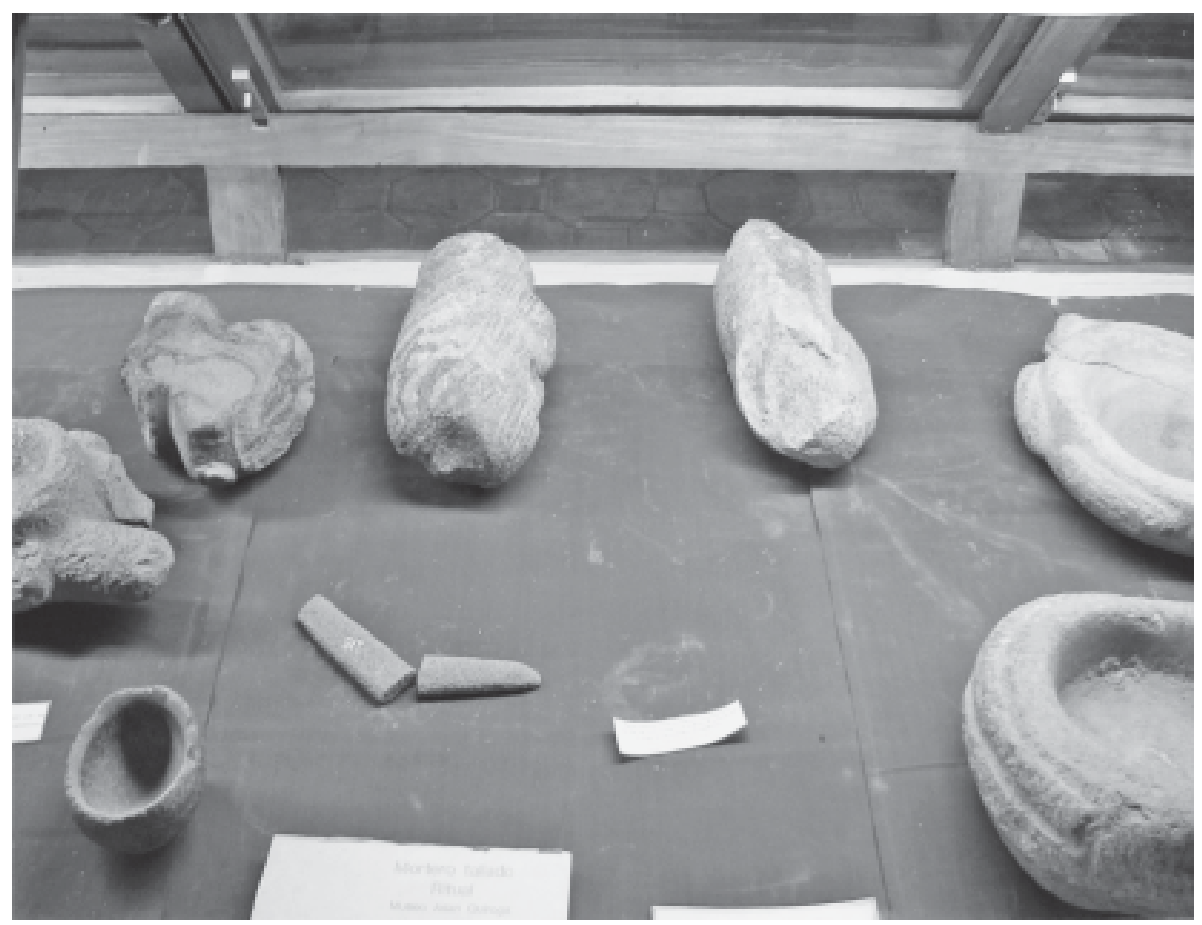

Fig. 9. Ejemplo de materiales de piedra de diferentes períodos juntos en una misma vitrina.

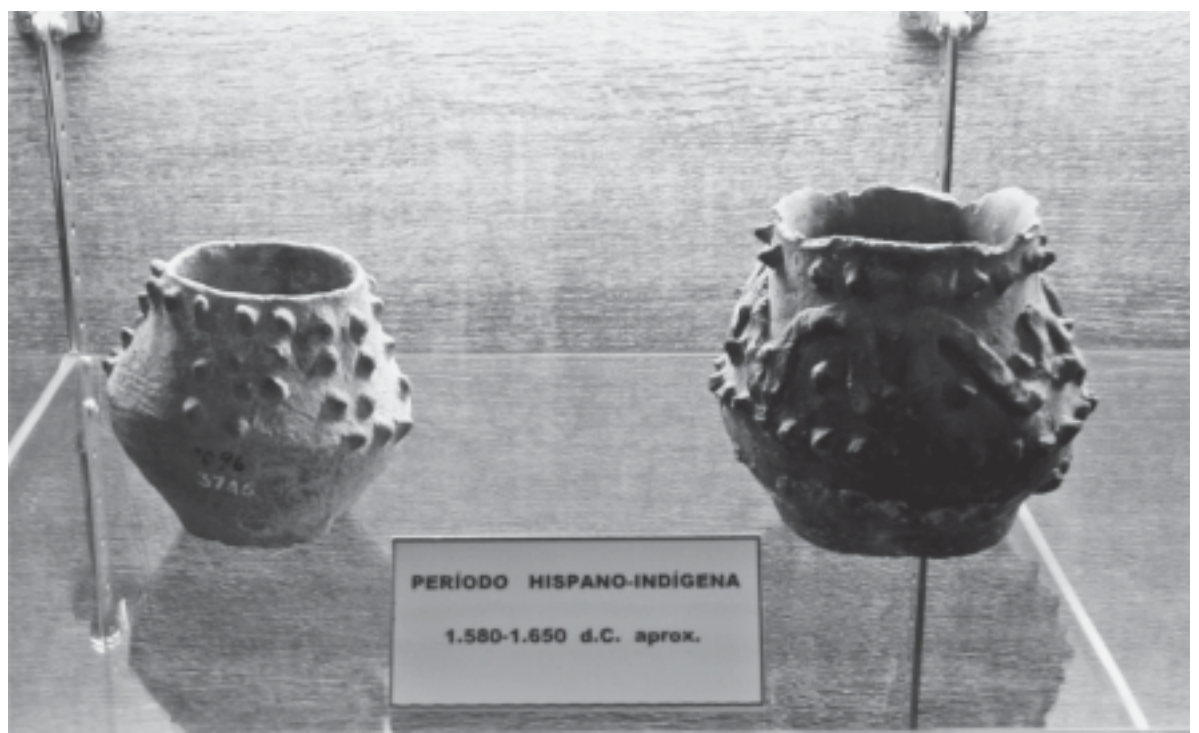

Fig. 10. Vasijas del período hispano-indígena (colonial) exhibidas en la sala de arqueología. 
vitrinas $y$, sobre todo, la posibilidad de reunir en una sola de ellas, objetos de diferentes períodos (por ejemplo "objetos de metal" o "collares de cuentas") parece indicar que las rupturas, si las hubo, no alcanzaron a marcar una discontinuidad de importancia en el flujo histórico, al menos no uno que deba incidir en el flujo de la circulación. Un corte más marcado, en cambio, puede ser experimentado cuando uno pretende ingresar a la historia colonial. Esto es, en principio, porque la muestra está montada en otra sala, pero más importante aún, por los objetos que caracterizan a este período (Fig. 11). Vamos a desarrollar esto más detenidamente para ver la naturaleza del corte.

Sabido es que todo corte en la historia resulta, por fuerza, arbitrario. Esto dice en primera instancia que podría haber sido en cualquier otro momento, por ejemplo tras la expansión incaica o las guerras de la independencia, pero también nos obliga a preguntar por el motivo de la elección. Po- demos acercarnos a una respuesta si analizamos los objetos presentes y los ausentes en cada sala. Para ingresar a la sala colonial se debe transponer una puerta que se ubica a un costado del salón arqueológico, como indica el cartel montado sobre un dintel. Esto implica, por lo tanto, que lo arqueológico quedó atrás en el espacio y en el tiempo. Entre los objetos exhibidos en la sala colonial se destacan un pesado carruaje de la década de 1850 donado por los descendientes de un gobernador (Fig. 12), el sable y mandil de la montura del Teniente Coronel Estanislao Maldones (1854-1934) (Fig. 13), máquinas de escribir, una colección de armas de fuego del siglo XIX y comienzos del XX, planchas de hierro (para planchar ropa), moldes de velas, mates (para tomar mate), estribos de madera, entre otros. Ninguno de los objetos expuestos en la sala colonial corresponde, de acuerdo a su cronología, al período colonial, sino al republicano. No es que el museo Adán Quiroga no posea objetos del período

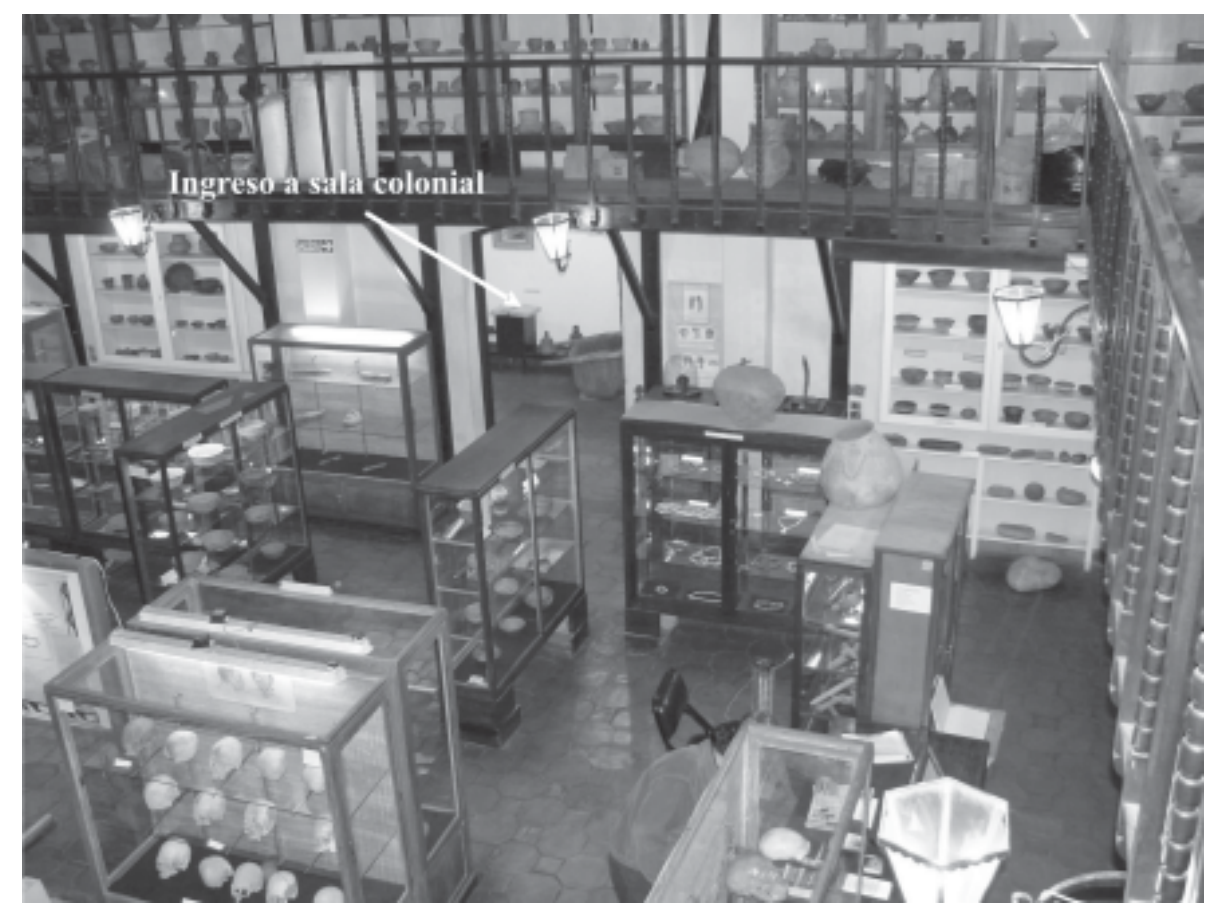

Fig. 11. Vista del acceso a la sala colonial desde la sala de arqueología. 


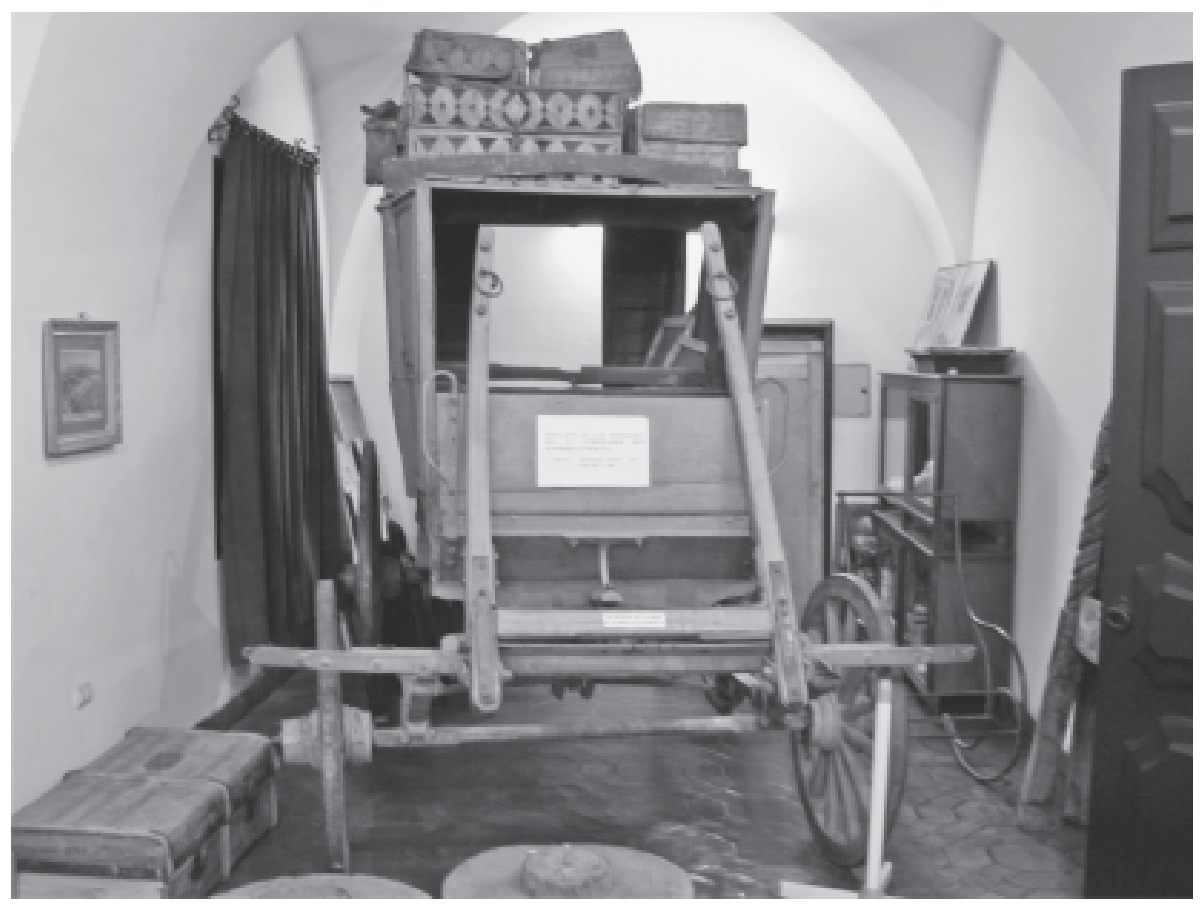

Fig. 12. Carreta exhibida en la sala colonial (ca. 1850)

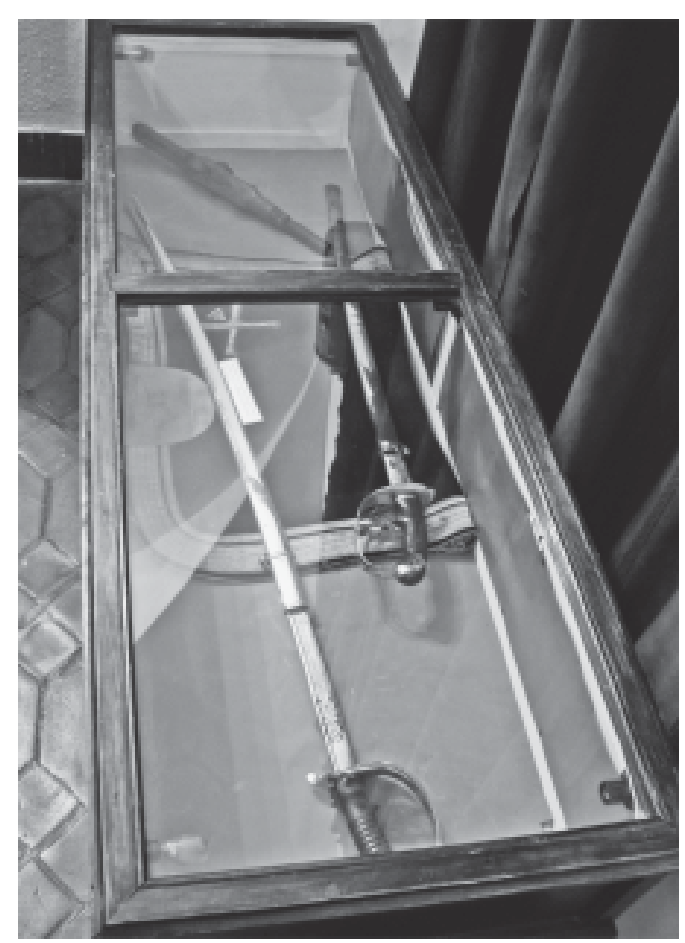

colonial, sino que estos no están en la sala colonial. ¿Donde están entonces? Los objetos que sin duda corresponden a momentos del coloniaje español son la cerámica Caspinchango y un collar de cuentas de vidrio que están expuestos en el salón de arqueología. También hay allí unos tupus (alfileres para sujetar la ropa) que podrían ser de época colonial. ¿Por qué los objetos coloniales no están en la sala colonial y en cambio si se expusieron allí otros de épocas más recientes? Se nos ocurre un solo motivo: porque los objetos coloniales que posee el museo Adán Quiroga fueron hechos o usados por los indios, es decir, son indígenas. De este modo podemos entender también el motivo por el cual es la sala de arqueología la que alberga el arco, las flechas y el textil vegetal, todos ellos de reciente confección por algún grupo indígena chaqueño, textiles de lana de origen

Fig. 13. Sables y mandíl pertenecientes al Teniente Coronel Estanislao Maldones (1854-1934). 
también reciente 0 incluso los trajes de la comparsa "Indios Diaguitas y Calchaquíes" de Mutquín donados hace sólo un par de años por quienes los confeccionaron (Fig. 14). Nada en la sala colonial representa a los indígenas. ${ }^{4}$ Se trata, en cambio de objetos que remiten más a una idea de lo "criollo" (los mates, las espuelas, los moldes de velas) y a la administración estatal (los objetos militares, la máquina de escribir "planillera", etc.). Como un acto de prestidigitación, la ubicación espacial de los objetos asimiló lo indígena a lo arqueológico, lo relegó al pasado remoto al tiempo que lo excluyó de la historia reciente y del presente. Como una burla del destino, en la sala colonial podemos ver el sable del Teniente Coronel Maldones al tiempo que permanecen invisibles los indios que fueron muertos por éste en las genocidas conquistas del desierto y del Chaco donde participó y alcanzó su grado militar. La exhibición del Museo Adán Quiroga es, entonces el alegato de la extinción de los pueblos indígenas.

El público que visita el Museo Adán Quiroga marca picos de hasta 2000 visitantes en el mes de julio. Sin embargo, lo relevante es que la mayoría de ellos son alumnos de los niveles EGB y Polimodal que asisten bajo la tutela de los docentes de historia y ciencias sociales. Por lo tanto, una gran parte de los jóvenes de la ciudad de Catamarca recorrieron alguna vez su exhibición y por lo tanto aprehendieron su narrativa.

Creemos que son importantes las dificultades que podrían tener los estudiantes, y en general todo visitante, para articular una crítica al discurso histórico del museo. En primer lugar, porque la visita es parte de la

(4) Esto no implica que los objetos del período republicano que se hallan en las vitrinas no fueran utilizados por indígenas, sin embargo, la selección y disposición de los objetos expuestos en la sala colonial, mas que remitirnos a los distintos usos de estos objetos por diferentes sujetos sociales entre ellos los indígenas, se vinculan a mostrar el proceso de consolidación del estado nación argentino. enseñanza impartida por sus maestros; en segundo lugar, porque el relato cuenta con el aval del museo como institución (Alvarado et al. 2003, Funari 2001, Endere y Curtoni 2003, Podgorny 1999), pero lo más importante quizás, sea el hecho de que se trata de un relato que no está enunciado. De hecho, no es aprehendido como una forma discursiva, sino que lo es por medio de la experiencia corporal que resulta del transitar entre los objetos. Este transcurrir por pasillos y salas que delimitan espacio-temporalmente la forma en que debe ser reconocida y narrada la historia de Catamarca, no sólo demarca una forma de aprender la narrativa, sino también de vivirla, y de esta manera, queda impresa en los cuerpos de aquellos que experimentan la visita. Esto que es aprendido por el cuerpo “...no es algo que se posee, como un saber que uno puede mantener delante de sí, sino algo que se es. [En este sentido, este saber nunca está] separado del cuerpo que lo porta, sólo puede ser restituido [hecho discurso] al precio de una especie de gimnasia destinada a evocarlo..." (Bourdieu 1991: 124125). Cuando sucede esto, las posibilidades de objetivación de estos saberes y por consiguiente su sometimiento a crítica, entra ya en conflicto no sólo, como ya mencionamos, con la enseñanza formal discursiva de la escuela y la legitimidad institucional del museo, sino que también encuentra una resistencia que proviene del cuerpo mismo del individuo, de esa memoria corporal aprehendida durante la visita al museo. De esta manera el museo re-estructura el pasado, definiendo la manera en la que se cuenta la historia a través de la presentación de los objetos. Es decir que estos objetos son colocados en el museo de una manera tal que constituyen un sistema estético que crea y fija los significados (Shanks y Tilley 1987).

Las narrativas arqueológicas que se constituyen en discursos públicos acerca de lo indígena y su historia dejan un mensaje claro: los indígenas, cuya existencia es científicamente contrastable en el pasado, no han llegado al presente. Se entiende, 


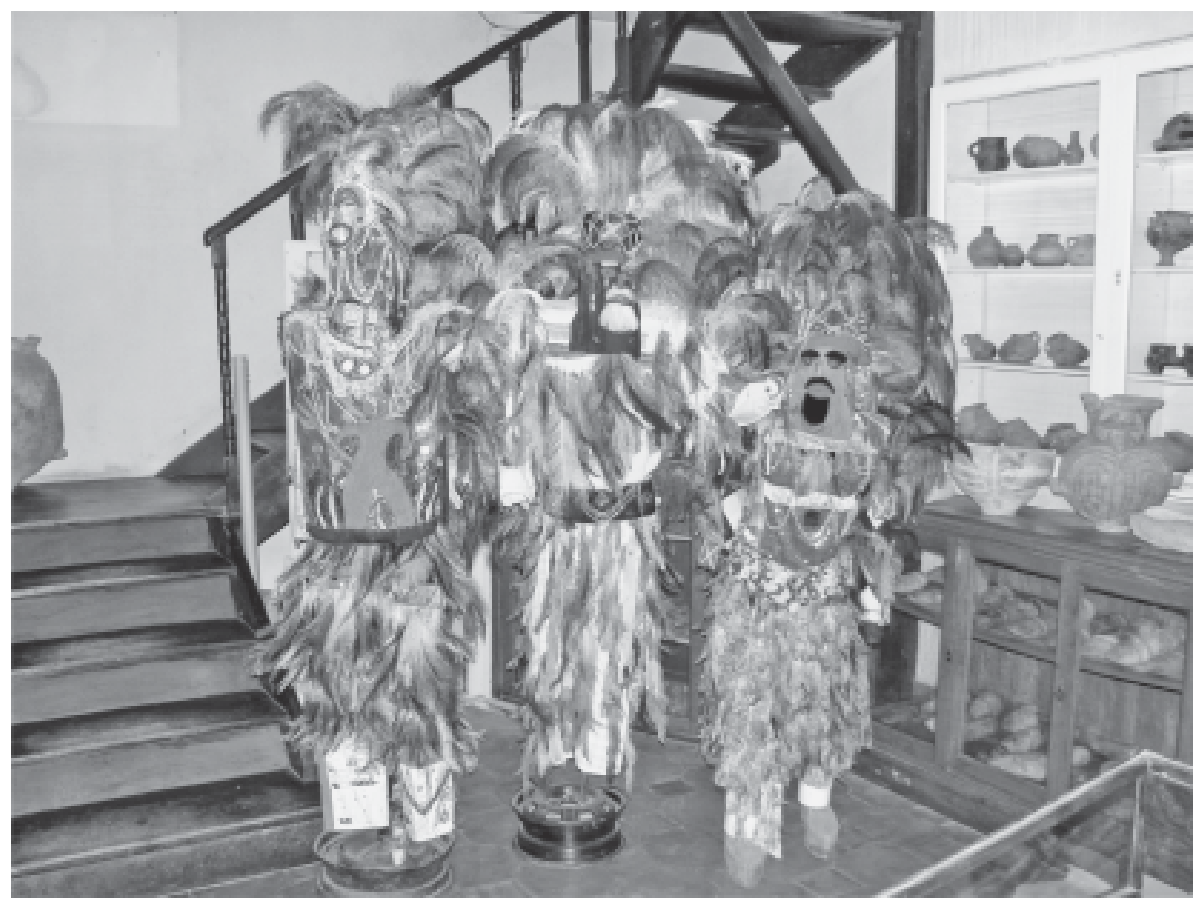

Fig. 14. Disfraces de la comparsa "Indios diaguitas y calchaquíes" de Mutquín, de reciente confección, exhibidos junto a vasijas prehispánicas y coloniales en la sala de arqueología.

entonces, por qué para muchos los indígenas están de más en el futuro. Esta narrativa en el contexto histórico-político particular en que vivimos, donde la presión sobre las tierras de comunidad se ha incrementado, produce que las posibilidades de condensación o sutura de una identidad indígena queden estrechamente limitadas. Esta limitación es doble: por un lado, la enseñanza formal de la escuela, tanto en los centros urbanos como en las mismas comunidades campesinas, narra una historia de aniquilación de lo indígena, reafirmada frecuentemente por los textos arqueológicos, mientras que, por otro lado, esta narrativa es materializada y así fijada en los museos a manera de monumentos de una memoria 'inmemorial'. Esta doble limitación promueve el no auto-reconocimiento y en aquellos casos en los que éste se produce, promueve la deslegitimación del mismo por parte de los otros no indígenas, apareciendo en el repertorio de estigmatizaciones sobre el indio, el sino del "indio trucho". ${ }^{5}$

No pretendemos en este trabajo haber descubierto "el mensaje oculto" del Museo Adán Quiroga pues no existe tal cosa. En su sugerente teoría de la desnudez arqueológica Gnecco advirtió sobre la futilidad de intentar semejante tarea. Indicó que "todas las relaciones están en la superficie y que no es posible develarlas, puesto que nunca han estado ocultas, sino solamente describirlas" (Gnecco 2003:7). El desafío, entonces, consiste en cambiar la mirada de modo que resulte visible aquello que nunca hemos mirado y que, sin embargo, siempre fue evidente. Nos preguntamos de un modo más concreto ¿cómo poner en crisis el mensaje del

(5) Suele usarse el término "trucho" para designar algo que es falso, pero que tiene pretensiones de pasar por auténtico. 
museo? Lo primero que se le viene a uno a la cabeza es la necesidad de modificar la disposición de la muestra de manera que ese corte tajante en la narrativa histórica resulte, al menos, atenuado. Sin embargo, implicaría considerar que se trata de un "error" en el relato. Esto, a su vez, significaría que existe un relato correcto de la historia uno que, subsanados los errores, resulta verdadero. Por ese camino, sin embargo, sólo terminaríamos consagrando una nueva narrativa hegemónica con sus propios cortes, omisiones y negaciones cuando, en realidad, lo que deberíamos hacer es mostrar al público que visita el Museo la multiplicidad de interpretaciones posibles acerca de la historia. El contraste de los relatos no sólo pondría en foco la situacionalidad de cada unos de ellos, sino también habilitaría la reflexión sobre su sentido político. Esto, claro, implica la creación de nuevas formas de exhibición que permitan experimentar distintas narrativas y sin duda que allí deberían participar distintos actores sociales, pero en especial las comunidades indígenas cuya historia es narrada por el Museo pero que nunca son, sin embargo, el sujeto que las enuncia.

Aunque en Catamarca son aún tenues, hay evidencias de que esta situación se está revirtiendo. En los últimos años otras voces han comenzado a disputarle a la arqueología y a la historia el lugar privilegiado de enunciación de discursos históricos del cual gozaron durante mucho tiempo (Funari 2001, Gnecco 1999, Segobye 2006a y b). Las comunidades indígenas haciendo frente al prolongado despojo al que fueron sometidas, se niegan a desaparecer. En este punto los arqueólogos no podemos evitar tomar posición. La encrucijada define dos caminos posibles: continuar relatando la extinción de los pueblos originarios, cuyas voces resuenan cada vez más fuerte, 0 comenzar a desandar la senda de aquella ruptura metafísica.

\begin{abstract}
We are interested here in exploring the role that plays the archaeological narratives in the construction or the image of indigenous people and their history in the province of Catamarca, Argentine. By a spatial and discursive analysis of the exhibition of the "Museo Arqueológico Adán Quiroga", we will sustain that this narratives relegates the indigenous to the pre-Spanish past, at the time that affirm their extinction during the first moments of the colony. This narratives could not only damage the possibilities of self identity affirmation by the indigenous people, but their create doubts in the legitimacy of those identities and the wrights that assist them.
\end{abstract}

Keywords: narratives, public archaeology, identities, indigenous, museum

\title{
Bibliografía
}

ALVARADO, J., J. MALDONADO Y A. SERNA

2003 Formas públicas de la arqueología y discursos escolares: poder, memoria y pedagogía a través de las representaciones del pasado.
En Arqueología al desnudo. Reflexiones sobre la práctica disciplinaria, editado por C. Gnecco y E. Piazzini, pp. 223-265. Editorial Universidad del Cauca, Popayán. 
BOURDIEU, P.

1991 El sentido práctico. Madrid: Taurus.

ENDERE, M. L. Y R. CURTONI

2003 Patrimonio, arqueología y participación: acerca de la noción de paisaje arqueológico. En Análisis, interpretación y gestión en la arqueología de Sudamérica, editado por R. Curtoni y M. L. Endere, pp. 277296. INCUAPA, UNICEN, Olavaria.

FUNARI. P. P.

2001 Public Archaeology from a Latin American Perspective. En Public Archaeology 1 (4): 239-243.

FUNARI, P. P.

2006 Conquistadors, plantations and Quilombo: Latin America in Historical Archaeological context. En Hall, M y Silliman, S (eds.) Historical Archaeology. pp: 209 - 229.

GALLOWAY, P. Blackwell Publishing, Oxford.

2006 Material culture and text: Exploring the spaces within and between. En Hall, M y Silliman, $\mathrm{S}$ (eds.) Historical Archaeology. pp: 42 - 64. Blackwell Publishing, Oxford.

GNECCO, C.

1999 Multivocalidad histórica: hacia una cartografía postcolonial de la arqueología. Universidad de los Andes, Bogotá.

GNECCO, C.

2003 El erotismo de la desnudez arqueológica. En Arqueología al desnudo. Reflexiones sobre la práctica disciplinaria, editado por C. Gnecco y E. Piazzini, pp. 5-24. Editorial Universidad del Cauca, Popayán.

HABER, A.

1999 Caspinchango, la ruptura metafísica y la cuestión colonial en la arqueología suramericana. El caso del noroeste argentino. En Revista do Museu de Arqueologia e etnologia. Suplemento 3:129-141.

HALL, M Y S. SILLIMAN (EDS.)

2006 Historical Archaeology. Blackwell Publishing, Oxford

JONES, $\mathrm{S}$.

1996 Discourses of identity in the interpretation of the past. En Graves-Brown, P., S. J ones y C. Gamble (eds). Cultural identity and archaeology. The construction of European communities. pp: 62 - 80. Routledge, Londres.

JONES, S.

1997 The Archaeology of Ethnicity: Constructing
Identities in the Past and Present. Routledge. Londres-New York

KRISCAUTZKY, N.

1999 Arqueología de Catamarca desde su poblamiento hasta la conquista española. CENEDIT, Universidad Nacional de Catamarca. Catamarca.

MC GUIRE, R.

1983 Breaking down complexity. Inequality and heterogeneity. En Advances in Archaeological Method and Theory Vol. 6: 91 - 142. Nueva York. Academic Press.

MC GUIRE, R.

1996 Why Complexity is Too Simple. En D. Meyer y P. Dawson (eds.). Debating Complexity. Department of Archaeology, University of Calgary, Calgary.

PIZARRO, C.

2000 La política cultural de las movilizaciones campesinas en Catamarca. Las narrativas sobre un conflicto por la tierra en una localidad rural de Catamarca. CENEDIT, Universidad Nacional de Catamarca. Catamarca.

PIZARRO, C. Y E. MORENO

2003 ¿Cómo construimos el paisaje de la Puna Catamarqueña, República Argentina?: Desde el pasado al presente. Trabajo presentado al 51 Congreso Internacional de Americanistas. Santiago, Chile.

PODGORNY, I.

1999 Arqueología de la educación. Textos, indicios, monumentos. La imagen del indio en el mundo escolar. Sociedad Argentina de Antropología, Buenos Aires.

SEGOBYE, A.

2006a Divided Commons: The Political Economy of Southern Africa's Cultural Heritage Landscapes - Observations of the Central Kalahari Game Reserve, Botswana. En Archaeologies. Journal of the World Archaeological Congress vol. 2 № 1: 52 - 72.

SEGOBYE, A.

2006b Historias estratificadas e identidades en el desarrollo de la arqueología pública en el Sur de África (traducción de C. Gnecco). En Arqueología Suramericana/Arqueología Sul Americana Vol 2 № 1: 93 - 118.

SHANKS, M. Y C. TILLEY

1987 Re-Constructing Archaeology. Cambridge University Press, Cambridge.

TRIGGER, B.

1994 Historia del pensamiento en arqueología. Crítica. Barcelona 